\title{
Improvement of the Corporate Loan Process in the Turkish Banking Sector: A Model
}

\author{
Prof. Dr. Semra Birgün (Beykent University, Turkey) \\ Prof. Dr. Sudi Apak (Esenyurt University, Turkey)
}

\begin{abstract}
The aim of the present study is to develop a model for the integration of lean thinking into the corporate loan process with a special focus on the utilization of the value stream mapping technique. In line with this aim the study proposes a three-legged model specifically for the corporate loan processes of banks in Turkey as a developing country pursuing to integrate into the global financial world. The three dimensions included in the model are operational dimension, staff dimension and customer experience dimension. The study argues that by applying the proposed model based on the lean six sigma approach, banks can achieve and sustain a high level of improvement that would increase speed, value creation, cost-efficiency, profitability and customer satisfaction and reduce waste, processing time and effort, duplication and prolonging of transactions, redundancies, risks and errors in the whole corporate loan process.
\end{abstract}

\section{Introduction}

Globalization and increased competition require new organizational structures. In order to keep up with rapidly changing trends and the challenges in the financial world, financial organizations are required to follow new finance trends and functions. They have to constantly analyze, redefine and restructure their managerial, operational, organizational processes and procedures to achieve and sustain continuous improvement. In order to fulfill these requirements and survive in the competitive business environment, financial organizations have to perform complicated and multi-dimensional actions oriented toward improvement besides their regular actions toward survival and profitability.

Under such circumstances, the concept of lean management has emerged as an approach that provides organizations the opportunity to lean all these complex, multi-layered and interrelated processes. In basic terms, "lean thinking is striving to achieve perfect efficiency within a business model - with a strong focus on meeting the customers' needs through continuous improvement. Lean thinking mean cutting out unnecessary or 'waste' activities to decrease lead times through the development of the most efficient and cost effective, customer focused processes" (Akdeniz 2014).

Lean management focuses on continuous improvement, reducing waste and increasing value creation at all levels of an organization. It appears as a corporate mind-set that promotes simplification and clarification of work procedures, reducing variation, and increasing customer-value orientedness.

Although lean management applications originated in the manufacturing industry, its full application in the financial services sector is relatively limited. The present paper argues that banks in Turkey should invest on the application of lean management to the corporate loan process management. Drawing on this idea, the paper proposes a three-legged model for "leaning" the operational, staff and customer related processes for the banking sector in Turkey as a developing country pursuing to integrate into the global financial world.

The remaining of the paper is structured as follows: Section 2 presents a brief overview of the challenges in the corporate loan process. Section 3 discusses the basic principles and practices of lean management and six sigma. Section 4 is devoted to the integration of lean six sigma into the corporate loan process. Last section presents the conclusions and suggestions.

\section{Corporate Loan Process}

Corporate loan is a key economic factor that determines the relationships between firms and banks in the banking sector. If corporate loan process is operated effectively, the bank enjoys a superior status in the eyes of its clients and the bank's profitability and market share increase.

One of the critical phases of the corporate loan process is corporate loan decision making (Zimmer in Bergeron et al., 1997) and the loan application process. Mačerinskiene and Ivaškevičiūte argue that 6 main qualitative indicators are evaluated to assess a legal person's creditability: "the history of cooperation with the customer; evaluation of the ownership structure; competitive status of the customer; evaluation of customer's activities; evaluation of management and quality of the accounting" (Mačerinskiene and Ivaškevičiūte, 2008).

Despite the fact that banks attribute great importance to the corporate loan process, the process is open to defects, deficiencies, human errors and delays which would adversely impact profitability, customer satisfaction, value creation, and cost and time efficiency. 
In terms of banks, low quality of the bank staff; improper procedures; delays in decision-making and approval processes that arise when boards of directors do not meet in a timely manner; and the problems arising due to poor coordination among a related branch, management and general management negatively affect the loan process. Such problems create troubles in the process that lead to waste of resources such as the duplication and prolonging of the transactions and cause discontent and dissatisfaction due to late reply.

The present study proposes a three-legged approach for the integration of lean thinking into the corporate loan process with a special focus on the utilization of the value stream mapping technique. The study aims at improving the process with the purpose of reducing waste of resources and increasing client satisfaction. Consequently, advantages to be obtained by the improvement of the process are presented.

\section{Lean Management}

The concept of lean is commonly used in the manufacturing industry for decades. In basic terms, lean is a holistic and sustainable approach of management processes of an organization, a business strategy based on creating value for the customers, while eliminating waste and deficiencies in the process (Văduva, 2011). Another commonly used approach in organizations to eliminate variability and reduce waste in processes is six sigma which is heavily based on the utilization of statistical tools (Banuelas Coronado and Anthony, 2002).

Lean management is a management philosophy that aims at a continuous improvement of a company's value creation capability by engaging all employees. In order to follow this philosophy, the core idea of lean management is to reduce any kind of waste (Womack and Jones in Leyer and Moorman, 2014).

With a full understanding of the various forms of waste and value-added time and effort concepts as well as the requirements of true efficiency, Henry Ford was the first person to integrate an entire production process completely. The result was a huge amount of profit effect and one hundred fold in less than a decade. Ford's approach was revisited by Toyota to establish the Toyota Production System, the origin of lean (Văduva, 2011). Since then lean management concepts have been further developed and enhanced (Ohno in Leyer and Moorman, 2014).

Main characteristics that define lean management are identified as follows:

- $\quad$ the main focus will always be providing customer value

- implementing lean management means adopting a philosophy of continuous and incremental improvement at all levels of the company

- after having studied customer demand, the company will provide exactly what's needed at the right time

- $\quad$ creating a continuous flow in a value-added effective manner

- $\quad$ using techniques for reducing variation and eliminating waste

- $\quad$ respecting people

- $\quad$ adopting a long term approach (Văduva, 2011).

In a nutshell "lean thinking seeks to eliminate waste, specify value, line up value-creating actions in the best sequence, conduct those activities without interruption whenever someone requests them, and perform them more and more effectively" (Womack and Jones in Trent, 2008). Lean management, on the other hand, "must be viewed as an integral system of four, interdependent elements: leadership, culture, team, and practices and tools (Fliedner, 2012).

Banks are among the financial institutions that benefit from and apply lean principles to improve their business processes, standardize procedures and create customer value. By the application of lean practices and techniques, banks can save time, carry out customized activities, eliminate wasted time and effort and thus reduce the total business costs, provide fast and high quality services and increase customer satisfaction, reduce routine, integrate the staff into the improvement, design and application processes and increase their enthusiasm (Văduva, 2011).

The so called 5S are an example of lean practices that should be applied in banks:

1) sort - sorting office materials, maintenance materials or other tools is fundamental for delivery and quality of quality and timely banking services. For instance, sorting emails, files and archive is a Lean activity for any bank employee;

2) straighten - the tools of banking services should be arranged in standard locations for consistent and easy access. These include data bases, references, operating procedures, reports.

3) scrub - means to maintain service tools in a neat and clean condition.

4) systemize - at all levels, as part of staff regulation routine, employees should go through the work environment and maintain;

5) standardize - it is essential for a bank to exercise discipline in maintain the work place and institute processes in a standard manner (Văduva, 2011).

In order to restructure and improve their systems with the further aim of achieving effective and efficient operational and customer processes, banks and financial service providers use the approach combining lean and 
six sigma, frequently referred to as Lean Six Sigma (LSS), "a method that has proven to be of great value for structurally improving customer value streams" (Kuiper et al., 2016).

Six Sigma is defined in the business context as "... a business improvement strategy used to improve business profitability, to drive out waste, to reduce costs of poor quality and to improve the effectiveness and efficiency of all operations so as to meet or even exceed customers' needs and expectations (Antony and Banuelas Coronado, 2001).

Different industries utilize these approaches at several dimensions of their manufactural, financial and operational processes to obtain operational and strategic advantages against their competitors. They consider lean management and the application of six sigma as a process of improvement through simplification.

\section{Integration of Lean Six Sigma into the Corporate Loan Process}

Corporate loan process management is one of the fields in which lean philosophy can be followed as a corporate mind-set for the continual process improvement. Adopting this philosophy throughout a company is supposed to be positively correlated with higher efficiency (Dahlgaard and Dahlgaard-Park in Leyer and Moorman, 2014). Corporate leaders often focus on the "tools and techniques" of their company. But what empower the businesses are the management systems and the human spirit that give their purpose (Văduva, 2011).

Though it has been deployed and developed mostly in the manufacturing industrial business for decades, it has not been utilized enough in the financial services industry. As integrative and multidimensional approaches, lean and six sigma are closely related to measuring and assuring quality as well as improving customer value streams. Precisely at this point, implementation of value stream mapping emerges as a critical tool for the true adoption of lean six sigma as managerial philosophy.

As a lean management method, value stream mapping enables organizations to thoroughly analyze and deeply understand their current practices and state. It also makes it possible to identify problems, consider their solutions and design prospective practices and state for the whole processes of the organization.

Keeping basic lean principles in mind, banks can map the value stream to eliminate waste, perceive transactions as products, target to increase value and decrease waste by regularly using KAIZEN to promote effectiveness of the activities (Văduva 2011).

Lean finance organizations have three components: an operational organization that excels at transaction activities, a series of knowledge or expertise centers that focus on problem solving, and the business partners who are working within line organizations (Randall, 1999).

While Gunn suggests these as the three components of the financial organizations in general, the present study offers a three-legged approach specifically for the corporate loan processes of banks in Turkey. The three dimensions involved in the approach proposed in the present study are operational dimension, staff dimension and customer dimension. As a holistic approach, it considers these three dimensions not in isolation but as the ones which are interrelated and interconnected. The present approach embraces the organizational structure of a financial organization as a whole and suggests to consistently and systematically deploy lean six sigma principles and techniques at all three levels with the ultimate aim of improving their customer value streams.

It is suggested that "improvement of a customer value stream usually involves different improvement projects that focus on different aspects of the value stream. Lean six sigma practitioners can deal with complete value streams by dividing it into subprocesses and sequentially optimizing them" (Kuiper et al., 2016).

In what follows, the present study discusses the three dimensions with a focus on the integration of lean six sigma principles into each dimension of the corporate loan process in banks.

\subsection{Improvement of Operations}

In order to outperform in the highly competitive business and finance world, banks are required to shift to simpler systems focusing on the overall business and activities. They have to develop more flexible systems to better and quickly respond to specific customer needs and demands under the changing local, regional and global conditions. In order to enhance their operational performance, banks need to be lean at each operational level.

In Turkey corporate loan process generally follows the following steps:

1. The branch of the bank receives the loan request from the customer.

2. The branch evaluates the request for pre-approval and delivers the request to the general management.

3. General management evaluates the request and delivers it to the board of directors for the final approval.

4. Board of directors makes a decision and delivers it to general management which sends it back to the branch.

5. The final decision is communicated to the customer by the branch.

However, the process is negatively affected and even blocked due to procedural and operational problems. Timeconsuming transactions and delays in decision-making and approval processes and improper procedures have an adverse impact on the whole process. Furthermore, problems arising due to poor coordination among a related branch, management and general management decreases operational effectiveness and efficiency as well as 
customer value and satisfaction. All these bring along waste of resources, duplication and prolonging of the transactions and increase in costs, resulting in low quality service.

Within the framework of lean six sigma approach, in order to eliminate the mentioned problems and improve the operations involved in the corporate loan process, banks should perform value stream mapping as the first and essential step. Proper application of value stream mapping enables banks to identify the defects and inefficiencies in the corporate loan process.

The value stream consists of all those activities that are necessary to produce and offer a product or service according to the identified customer needs (Bowen and Youngdahl in Leyer and Moorman, 2014, p. 1369). Creating flows within the value streams minimizes delays and wasted time when processing customer orders in a value stream (Koskela in Leyer and Moorman, 2014). Through value stream mapping, banks can improve their organizational processes by becoming fully aware of every single step of their work flows.

Specifically, for the corporate loan processes, one major aspect to be dealt with concerns the proper division, description and fulfillment of tasks. Banks can identify whether the detailed and specific task definitions are in place, and, if yes, whether the branch and the general management fully perform their predefined roles without increasing workload, wasting work force, causing duplication in the flow. One strategy can be providing the branch with the opportunity to take certain initiatives and act independently where necessary. This, without doubt, necessitates proper and continuous training of the related branch staff, which is discussed in the following subsection.

In line with the data obtained from the map, banks can see the exact points to apply their lean approach to improve the processes that are critical for performance, profit and value.

Another major operational aspect concerns the automation of business process by means of the utilization of information technologies (IT) such as modeling, monitoring and data integration tools and process management software. Through the need-specific use of IT, banks can increase their operational efficiency and increase their leanness by monitoring the collection, communication, documentation and reporting of accurate data concerning for instance customer balance sheets, financial background information of customers evaluated by the bank for making decision in the corporate loan process. Specifically, banks can increase the satisfaction of their internal and external customers by using software that produces accurate reports for specific customer needs.

Through the adoption of lean as an operational strategy, banks can eliminate the complexities in the process, increase revenues and lower costs, reduce wastes and increase customer satisfaction.

\subsection{Improvement of Staff}

Human dimension of an organization is of central importance for fully and practically implementing lean six sigma approach in financial organizations. In the context of corporate loan process in banks, preparing detailed task definitions, workloads, working methods and supporting the effective flow of working procedures by means of the utilization of information technologies do not yield the desired results unless they are applied by the staff members who have internalized lean thinking.

Thus, it is essential for organizations to adopt lean thinking as the core of their corporate philosophy. They should create and maintain a corporate culture that allows the internalization and application of lean practices at all levels by all staff members. The first step to achieve these interrelated objectives is to raise awareness of the staff members about the advantages of lean and value-oriented thinking. As underlined by Leyer and Moormann, "[L]ean thinking has to be embedded in the mind of its employees. Ways have to be found so that employees really perform their daily work in a lean way. This is much more important than using specific tools and techniques when applying lean management (Leyer and Moormann, 2014). Moreover, in addition to performing routine procedures, staff members should be able to make their own contribution to the process improvement on the basis of their individual experience and creativity (Văduva, 2011).

Effective and sustainable implementation of lean six sigma approach depends on staff members' continuous focus on value-creating processes, their professional skills of using relevant tools in an independent and creative manner as a natural part of their individual working system. For the achievement of all these requirements with the aim of improving corporate loan process through lean six sigma approach, organizations should provide continuous and multi-dimensional training opportunities for their staff.

In order to act independently and responsibly in line with the corporate guidelines with clear instructions on the standardized processes, related staff members should be trained to be the competent leaders for their professional activities. They should be aware of their role in creating value in the whole organizational system, which should be reflected on their attitudes. Continuous professional training should become a permanent component of the corporate culture and the staff members should be open to continuous personal training in order to serve for the creation of value in the regular flow of the stream.

Continuous training should also target the improvement of the technological and communicative skills of the staff members in order to enable them to keep up with the fast changing business environment. In contemporary world, "'new' finance role requires the ability to communicate complex financial data to individuals in such 
departments as marketing, information technology, and operations during joint efforts to develop creative solutions to business issues. As the function continues to evolve, companies are broadening the job requirements for financial positions to include an emphasis on interpersonal, project management, and leadership skills" (Randall, 1999).

Corporate loan process is definitely a field open to take the utmost advantage of all these practices, thinking ways and innovations. With the help of training their staff, organizations can reorganize their corporate loan processes as an efficiency- and customer-oriented process to produce more value and less waste of time and resources. In this way, banks can have the opportunity to focus on the total value chain and increase the level of service quality and profitability.

To concretize, a properly trained staff member at the branch of a bank can fully and effectively carry out the required transactions and procedures predefined in the related task divisions and thus can obtain an accurate and complete financial data of the customer and deliver it to the general management in a way to eliminate any duplication of the relevant transactions. By acting as the leader of the sub-process, that staff member can complete a considerable amount of the loan processes including the collection and control of the required financial data without directing the customer to different organization units and causing delays, uncertainties and repetitions. In this way, the general management will have more time to guide their subordinates instead of wasting time for performing operational tasks. This would definitely increase the speed of procedures and hence customer value and satisfaction. Moreover, managerial and sales staff would be much more focused on sales-oriented activities with the aim of boosting the number of the customers with less risk, a high credit worthiness and high potential of profitability.

\subsection{Improvement of Customer Experience}

In pursuit of value-creation and value-perfection, the third area of improvement should be customer experience. A two-dimensional strategy might be deployed for producing value in this area: restructuring and standardizing the principles, rules and processes concerning the communication of the bank staff with the existing and prospective customers, and, at the same time, allocating room for flexibility and creativity to be used by the staff depending on customer needs, demands and expectations.

A significant example for the gain obtained through lean activities is that of a Latin American bank which brought lean to its sales operations and thus increased customer appointments by $50 \%$ and total sales volume by $20 \%$, while reducing its non-sales staff by more than $20 \%$ (Ilebrand et al., 2011).

Within the frame of the improvement of customer-related processes, one major step to be taken is to prepare a kind of map that would provide transparency of procedures, transactions and the progress of the flow both for the staff and customer so that customer can follow the overall activities starting from the loan request to the final approval while the staff conduct and monitor the application process without any waste and risk of incorrect and repetitive operation. Furthermore, each unit can easily identify the role/function of itself and other units, which would also lead them to offer need-based, innovative ideas for the further improvement of the corporate loan process.

In the context of customer-related processes, another major step concerns the standardization and automation of certain procedures which are common for most of the corporate loan process such as collection of data on the credit history, cash flow history, financial statements, balance sheets, income statements.

In order to eliminate the risk of obtaining incomplete or inadequate data from the customer and of delays in the transactions and flow of the loan application, evaluation and approval processes, the communication with the customer should be carried out by a single member of the staff who strictly follows the pre-defined procedures and, where necessary, becomes the decision-maker to understand and respond to specific customer needs and demands and customizes other further required processes accordingly. This flexibility would contribute to the increase in customer value, shorten the time spent on operations and eliminate the waste of work force.

\section{Conclusion}

Banks, in line with their ultimate aim to achieve perfection in their operational, organizational and technological processes undergo a constant transformation process. They intend to eliminate complexities and achieve leanness at all levels of the organization. To achieve these aims, they should redesign their corporate guidelines, instructions, documentation, checklists, IT applications, corporate structure, job profiles and task definitions, and customerrelated documents etc. in a lean manner. They should apply lean six sigma principles, practices, techniques and tools to identify, analyze and eliminate defects, inefficiencies. To fulfill this objective, they should utilize value stream mapping technique as the first step.

True integration of lean six sigma into the corporate loan process requires the improvement of not a separate and single aspect of an organization but a holistic, long-term and substantial change. Thus, the present study proposes a three-legged integration model which focuses on operations, staff and customer for the banks in Turkey. 
Unlike traditional complicated practices in the corporate loan processes of banks, the proposed model suggests implementation of value stream mapping technique in the procedural and operational dimensions of the corporate loan process.

In order to eliminate waste, risks and uncertainties, to reduce cycle time and to enhance customer value, banks should ensure the clarity, applicability and functionality of task divisions and definitions and constantly monitor if the branch and the general management perform their predefined roles fully and without causing unnecessary increase in the workload, waste and duplication. Operational improvement should be supported by the needspecific use of IT to increase the operational efficiency and leanness. Banks can also increase customer satisfaction by using IT applications to produce accurate reports for specific customer needs.

Sustainable improvement of corporate loan process can be achieved through the adoption and internalization of lean principles and thinking by all staff members. Staff members should be aware of their role in creating value in the flow of the stream. At this point, training staff members in order to improve their technological, communicative and leadership skills is of critical importance. As the essential component of organizations, staff members should have a full knowledge of the whole corporate loan process and be able to completely understand customer needs to better respond to these needs.

As the third dimension, customer-related processes can be improved through the preparation of a map for the transparency of procedures, transactions and the progress of the flow both for the staff and customer. In this way, customers can follow the overall activities starting from the loan request to the final approval. On the other hand, the staff can conduct and monitor the application process without causing waste, incorrect operation and duplication.

For the further improvement of customer-related processes, another step to be taken is the standardization and automation of common procedures in the corporate loan process such as collection of data on the credit history, cash flow history, financial statements, balance sheets, and income statements.

For obtaining complete or adequate data from the customer and preventing delays in the transactions and flow of the loan application, evaluation and approval processes, the communication with the customer should be carried out by a single member of the staff who both follows standard procedures and makes decisions for customizing processes and shorten processing time on behalf of the customer. In the long run, the banks could have a higher opportunity to find and work with high profile customers, improve their existing customer profile and increase customer value and profitability.

To recapitulate, by applying the proposed model based on the lean six sigma approach, banks can achieve and sustain a high level of improvement that would increase speed, value creation, cost-efficiency, profitability and customer satisfaction and reduce waste, processing time and effort, duplication and prolonging of transactions, redundancies, risks and errors in the whole corporate loan process.

\section{References}

- $\quad$ Akdeniz, 2014. Lean Principles Explained. First Publishing, p. 1.

- Antony and Banuelas Coronado. 2001. “A Strategy for Survival”, Manufacturing Engineer, 80(3), pp. 11921.

- Banuelas Coronado and Anthony, 2002. "Critical Success Factors for the Successful Implementation of Six Sigma Projects in Organizations”, The TQM Magazine, 14(2), p. 92.

- Bergeron et al. 1997. "Application of MCDA to Corporate Loan Requests Evaluation”, Multicriteria Analysis, p. 453.

- Fliedner. 2012. Leading and Managing the Lean Management Process, New York: Business Expert Press, p. 2.

- Ilebrand et al. 2011. "Boosting Sales in Branch and Agency Networks through Lean", Lean Management: New Frontiers for Financial Institutions, Mckinsey\&Company, p.113.

- Kuiper et al. 2016. "Quality Quandaries: Improving a Customer Value Stream at a Financial Service Provider”, Quality Engineering, 28(1), pp. 155, 156, DOI:10.1080/08982112.2015.1089445.

- Leyer and Moormann. 2014. "How Lean Are Financial Service Companies Really? Empirical Evidence from a Large Scale Study in Germany", International Journal of Operations \& Production Management 34(11), pp. 1366, 1368, 1369, 1380.

- Mačerinskiene and Ivaškevičiūte. 2008. "The Evaluation Model of a Commercial Bank Loan Portfolio", Journal of Business Economics and Management, 9(4), pp. 274.

- Randall. 1999. “Challenges in Finance”, Strategic Finance, 80(9), ProQuest Business Collection, p. 32.

- Trent. 2008. End-to-End Lean Management: A Guide to Complete Supply Chain Improvement. J. Ross Publishing, p. 4.

- Văduva. 2011. "Lean Management in Banking”, in Annals of the University of Craiova Economic Sciences Year XXXXI No. 39, pp. 118, 119, 120, 121, 122, 123. 